\title{
The feasibility of XBRL application in the enterprise financial management advice and security research
}

\author{
Liucheng Zhang, Yuanqing Mao \\ School of Accountancy, Harbin University of Commerce, Harbin 150028, China
}

Keywords: XBRL; feasibility; enterprise financial management.

\begin{abstract}
The XBRL report is to establish the beginning of the standardization of accounting informationization in our country. XBRL report is in the accounting standards for enterprises under the premise of information disclosure of financial report. This paper attempts at standardization of accounting information system within the framework of research on accounting information standards, application of XBRL in our country enterprise financial management put forward some feasible Suggestions and related guarantee measures.
\end{abstract}

\section{Introduction}

With the deepening of the information of globalization and the concept of "Internet + " accounting information standardization technology committee and XBRL China organization set up for our country accountant the informationization development has brought a new situation, the situation in order to speed up the construction of standard system of accounting information sent clear signals. In recent years, we always focus on the research development of the XBRL and closely contact with international organizations. But at the same time of promoting XBRL standard, should pay attention to grasp the global. From the existing literature for the study of accounting informationization standard in our country still stays in the theory research stage, drawing out the standard for accounting information and accounting informationization standard's implementation of discussion, most are aimed at standard of XBRL taxonomy. In view of the current present situation of the application of XBRL environment put forward feasible Suggestions and measures.

\section{The feasible Suggestions}

Academics continue to advance the XBRL theory research and perfect. We are doing academic research has been emphasized the relationship between the theory with practice and theory to the tasks of the foundation. Currently in academia for XBRL environment realization standard formulation and implementation of enterprise accounting information has always been supportive of that in the study of XBRL application also has been the focus of the academic circles of project. At present academia to XBRL work embodied in the following four points:

(1)Apply to the state or relevant department, the XBRL as a key research project, after having obtained the national policy and financial support, the experts and scholars in-depth research and discussion, to promote and implement the XBRL theory basis.

(2) The XBRL academic seminars held on a regular basis. Study of XBRL wide-ranging exchanges, but also from the enterprise and society can be invited and make a study of the theory of the XBRL more accepting applications.

(3) Establish a good contact with the country's academia, and for foreign theory and practice of the reference to the achievements and experience to be selective, in learning and using for reference will not be able to break away from the actual situation of our country.

(4) Choose to have typical industries as the pilot, and carries on the detailed studies of XBRL application effect, experts and scholars to strengthen keep close contact with enterprises, forming good relations of cooperation, to realize the theory of the ultimate goal is to apply in practice. The study of XBRL all eventually will implement in practice. Only in the practice of soil can make XBRL will be improved. Research activities in academic circles, it is necessary to analyze the XBRL, find 
out the problems in practice, experts and scholars can into the grassroots, on enterprise training, make the enterprise under the guidance of the theory can better application of XBRL.

Promote the development of software technology and personnel training. Whether a country is prosperous and strong, this is determined by the development of science and technology, while the development of science and technology are making good, root cause lies in the innovation type talents. For countries that, for an enterprise as well. In the development of XBRL application software, our country does not yet have the ability of independent research and development, some companies in the treatment of XBRL application, its based on erp is compatible, although this is a kind of effective method, do not break but it is difficult to promote in our country, because only a handful of the enterprise application of erp in our country at present. Do not have capability to develop the XBRL application in domestic enterprises is always difficult to solve. The XBRL application also needs high quality talents. Thus talents play a key role in personnel training aspects to take effective measures as follows:

(1) the road is right, relying on science and education must go ahead, to science and technology in the network and software technology in China has made remarkable achievements, but also to new science and technology support, funding and technology, make the XBRL software development ability strengthens, and material and spiritual rewards for outstanding contributors.

(2) to the talent training and education work put in place to promote its quality was improved, but also to improve the ability and level of financial personnel, and make it from a full range of skills to the quality of ascension, and carries on the XBRL knowledge training, propaganda XBRL knowledge in the enterprise, the enterprise and social understanding of XBRL in stark.

(3) IT elite is rare precious resources, can introduce high-end education mechanism, at the same time to strengthen the study of domestic and foreign experience when first, to reduce the cycle of software development in our country.

The government increasing investment play a guiding role of the market. For XBRL has been vigorously advocate and promote our government, but the XBRL development situation is not optimistic, XBRL development is still difficult, the government also need to increase the intensity of support, and don't reject science promotion measures, in promoting XBRL environment accounting information under the standard achieved good development opportunities, the government's leading role should not be ignored.

(1) the XBRL taxonomy criteria is to be built, it is a challenge to various industries, companies will follow the standard based on XBRL documents, and play a guiding role to the market. To make a in-depth research on XBRL, and at the same time XBRL top-level design scheme is determined, and work out the overall development plan, it is not for accounting information construction in China to avoid link.

(2), from the perspective of the software technology. Government not only from the aspects of the policy level, the resources to support the XBRL software research and development, as well as information for the enterprise users to provide free software and training platform.

(3) to supervise enterprise using XBRL for enterprise information safety protection work, put an end to commercial secrets being stolen.

Improve enterprise enthusiasm and creativity of XBRL application. To know one shown in the main body of XBRL is enterprise, is also the XBRL environment, the company for the accounting informatization standard formulation and implementation of the key. From the enterprise point of view, the first period and the problems encountered by the resistance is normal, and may even make the enterprise to make ends meet, but short-sighted behaviour of avoid by all means, the application of XBRL and the trend of development is not around, from the long-term point of view, brings to the enterprise ", ", far in the "cons", make enterprise real experience the XBRL to bring positive change. Specific as follows:

(1) to put the eye in the long run, confined to the interests of the eyes is a short-sighted, XBRL environment to realize the accounting standard formulation and implementation of informatization at present resistance is bigger, invest more, is a big pressure for enterprise, but from a long-term point of 
view, keep up with the development of The Times, can grow up to be wet times, in the fierce competition to get a seat in the stand.

(2) to enhance the quality of the company. Shall be carried out from two aspects, one is to improve the quality of the staff, the measures taken for training. Recruiting talents to the society on the other hand, the inclusion of the professionals of high quality to the enterprise.

(3) obey the national arrangement, the response national policy, the XBRL pilot work to do, and should attach importance to information feedback, and in view of the existing problems and propose solutions.

Development and popularization of XBRL in our country is not easy, requires a lot of time and energy, but it is must to work, is indispensable to realize the accounting information. XBRL in our country's progress is not smooth, all kinds of difficulties hindering effect, in order to make the accounting information in XBRL environment standard smoothly in the future, must be solved in the XBRL application of all sorts of problems. And research the causes of problems, develop solutions, lay a good foundation for the development of XBRL.

\section{The safeguards}

Build the implementation of the standardization of accounting information. (1) government agencies. Current our country the current socialist market economy system and the economic accounting review operation system in the operation of the system construction are mainly borne by the government department, financial department as regulators in the system and the development of the industry regulator, must clear their own power and responsibility consciousness, leads the market in the specification and a sound system of industry regulation related for continuous optimization and improvement. At present, due to the particularity of our country economy and the development of the market imbalance factors, the economic development in China must be in a perfect sound regulator run development of the economic development. The financial sector as a function of exercise, must play a role of good its own value. At the same time, in the face of the current market of some folk organization capital, government finance departments should be correctly guide and specification, set up the correct development plan for them, and jointly promote the accounting system further improved and perfected. (2) the intermediary institutions Intermediaries as accounting audit system in the construction of a very important link, in actual regulation often plays an information transfer and industry development situation of communication. In the current market economy system is not sound in the construction of accounting system gradually perfected, intermediary agencies as information communicators, we are often in daily operation and management in the hands of the many new source. Intermediary institutions should, therefore, as far as possible in the system reform and improve the party and as far as possible for the system to implement the party provide certain help, realize the comprehensive reform. At the same time, the agency should also strengthen their internal reform and optimization of the construction of the system, strengthen the construction of personnel configuration and infrastructure, to achieve the organization efficient fast.

Adhere to the gradual implementation of strategy. The standardization of accounting information in accounting industry development planning has the incomparable role. In daily business operation, highly standardized intensive enterprise information often can let enterprise in the internal control, financial audits to reduce workload and get a more clear accounts. At the same time, for regulators to provide clear accounts accounting entries will help regulators in the audit supervision and reduce the wastage of the resources. To sum up, the height of the intensive standardization of far-reaching influence on the development of the enterprise operation and the function is lasting, in the operation of the enterprise in the development must be fully aware the problem, improve their financial regulatory standards and system operation.

(1)to distinguish the key. In accounting industry information construction and development of the specification, the XBRL based on their own authority and the scientific nature of guarantee the scientific rationality of it as a measure standard. Because the accounting industry standards, the overall standard is relatively complex. Therefore, the current conditions for a specific the 
implementation of the implementation of this standard system, perfect the related standards, use the clear development direction, according to the output of the accounting information in the process of information input is specific requirements in terms of optimization, implementation of the improvement of the overall look, and system construction.

(2)the first pilot. Due to the overall economic development layout and economic construction, the degree of market regulation in the current environment is not perfect enough. In our country in the XBRL technology promotion is necessary according to certain order and economic basis for the corresponding practice and exploration. Concrete practice of this technology and carry out the can start from large companies, in a certain large organizations to pilot the results of the concrete application of the technology practice to optimize the whole technical system of rectification, make it more in line with the industry in the future to promote the development of relevant standards and China's economic construction development planning of the whole system. At present, our country has begun in the stock exchange information submitted link review step by step to practice and optimize the system.

(3)to point with surface, gradually opened. The implementation of the system of emerging technologies and try in practice must fully conform to the actual economic situation and market situation. Thanks to the development of our country in this field are relatively weak, lack in your current phase of the implementation of the technology policy promotion way, step by step can be used in some areas, making the technology more in line with the market environment and economic development in our country.

\section{Conclusion}

In this paper, the system of XBRL application in our country to promote the large specification recommendations, according to the accounting industry in the process of marketization development present situation, the corresponding optimization problem, through research and analysis and digital data comparison, the author of the main conclusions are the following:

(1)Because of the economic system and economic environment and market economy environment, there exist certain differences, XBRL environment standard accounting industry development, improve the accounting information system must be gradual and specification.

(2)The XBRL in the specific use and promotion, the most effective experimental improvement scheme can from staffing and perfect information resources integration in practice.

(3)The XBRL standards in the process of operation specification used in the accounting industry, should be in operation mode, operation mechanism and reaches a certain balance and relevant quantitative standard and specifications.

(4)The informationization construction of standardized accounting system not only to correctly use XBRL technical environment, also should deal with the government, intermediary in reality the relationship between the companies and enterprises, the use of concrete should be combined in accordance with the international and national conditions; Fully and balance the interest subjects needs; The standardization of gradual advancing industry rapid development ordering.

\section{Acknowledgment}

This work is supported by National Social Science Fund Project 15BJY017.

\section{References}

[1] Fu Lijun. XBRL environment audit studies [J]. Friends of the accounting, 2011 (8)

[2] Chen Geng. Based on XBRL financial report affect audit discussion [J]. Journal of management informationization in China, 2016 (9)

[3] Zhang Liucheng.Research of Innovation and Entrepreneurship Education in Harbin University of Commerce[J]. Social Science and Humanity, 2015(76) , pp. 130-133 
[4] Zhang Liucheng.Application And Analysis Of Witkey Mode In Network Economy[J]. Advances in Social Science, Education and Humanities Research, 2015(31), pp. 178-181

[5] Zhang Liucheng.The Research and Innovation of Witkey Mode under the New Era[J]. Advances in Education Research, 2015 (11) , pp. 102-105.

[6] Zhang Liucheng.Research on the problems of the application of XBRL financial statement in small and medium sized enterprises[J]. Advances in Social Science, Education and Humanities Research, 2016 (59) , pp. 1421-1424

[7] Zhang Liucheng.Application-oriented Institutes Innovation Thinking and Practice of Talent Training Mode[J]. Advances in Social Science, Education and Humanities Research, 2016（59）, pp. 1425-1429

[8] Zhang Liucheng.Analysis on the future development of cloud Education[J]. Advances in Social Science, Education and Humanities Research,2016 (59) , pp. 1477-1480

[9] Zhang Liucheng.Research on the construction of education service platform based on Cloud Computing[J]. Advances in Social Science, Education and Humanities Research, 2016 (59), pp. 1481-1484

[10] Niu lili. XBRL development and its influence on audit research [J]. Modern economic information, 2016 (11) 